\title{
Influence of the Slag Density on the Splashing Process in a Steelmaking Converter
}

\author{
Miguel A. Barron, ${ }^{1}$ Dulce Y. Medina, ${ }^{1}$ Isaias Hilerio, ${ }^{1}$ and Gabriel Plascencia ${ }^{2}$ \\ ${ }^{1}$ Departamento de Materiales, Universidad Autónoma Metropolitana Azcapotzalco, Avenida San Pablo 180, \\ Colonia Reynosa-Tamaulipas, 02200 Mexico, DF, Mexico \\ ${ }^{2}$ Centro de Investigacion e Innovacion Tecnologica-IPN, Cerrada Cecati S/N, Colonia Santa Catarina, 02250 Mexico, DF, Mexico
}

Correspondence should be addressed to Miguel A. Barron; bmma@correo.azc.uam.mx

Received 24 October 2013; Accepted 3 January 2014; Published 13 February 2014

Academic Editors: S. Eckert and T. Yue

Copyright (C) 2014 Miguel A. Barron et al. This is an open access article distributed under the Creative Commons Attribution License, which permits unrestricted use, distribution, and reproduction in any medium, provided the original work is properly cited.

\begin{abstract}
The way in which slag density influences the slag splashing phenomenon in an oxygen steelmaking converter is numerically analyzed in this work. Several values of the density of the slag are considered, and their effect on the global mass balance and slag average volume fraction on the sidewalls of the converter is studied using isothermal, two-dimensional transient computational fluid dynamics simulations. Diameter of the slag drops is determined from the slag density and the impact velocity of the nitrogen jet. Besides, the effect of the nitrogen jet Mach number on the slag splashing is simulated and discussed. A qualitative comparison between the computer simulations and results from the literature is made.
\end{abstract}

\section{Introduction}

It is known that the wear of refractory lining in an oxygen steelmaking converter for raw steel manufacturing is a factor which greatly influences the production costs. In the last two decades, slag splashing has emerged as a new technology to extend the lifetime of the converter refractory lining given that this technology reduces the wear associated to thermal and chemical attack by slag and mechanical impact $[1,2]$. After the draining of steel, molten slag remaining at the converter bottom is splashed towards the converter sidewalls using a supersonic jet of gaseous nitrogen. Molten slag freezes at the converter walls and forms a protective coating that prevents the wear of the refractory lining. Nitrogen is injected into the converter through a water-cooled vertical lance which has several inclined convergent-divergent nozzles.

During the slag splashing process three main stages have been identified in the formation of the slag protective coating: transport of molten slag to the converter walls, adherence of the molten slag to the sidewalls, and freezing and hardening of the slag layer [3]. When the molten slag is transported to the converter sidewalls, two transport mechanisms are present: wash coating and ejection coating [4]. The first one occurs due to the bulk movement of the molten slag to rise above the initial level and the second one due to the ejection of slag droplets which adhere to the vessel sidewalls [5].

In recent years, several experimental studies on the slag splashing phenomenon have been reported. In these studies, physical scale models of the converter are employed, and cold water and air replace molten slag and nitrogen, respectively $[4,6,7]$. In $[4]$ it is reported that large nozzle inclination and lance heights increase the splashing and the main mechanism of splashing changes from ejection to washing as the viscosity of the liquid is increased. In [6] it is reported that the amount of slag splashed is increased as lance is raised, but beyond a critical value of the lance height splashing decreases. In [7] it is shown that when the jet flow rate is increased or the liquid viscosity is decreased, the lower regions of the walls are splashed at a much greater rate. It is also shown that by changing the lance height, more liquid is deposited in the upper regions of the vessel at the expense of lower regions.

On the other hand, some numerical studies of gaseous jets impinging on a liquid surface are reported using computational fluid dynamics simulations [8-10]. Agreement is reported between numerical and water model results; unfortunately, these studies are mainly focused on the jet-surface 
interaction and the prediction of the surface topography, rather than on liquid splashing. Recently, two studies [11, 12] by some of the authors of the present work were reported on the simulation of the slag splashing phenomenon using computational fluid dynamics, considering the dimensions of actual industrial converters and the influence of properties of molten slag. Particularly in [12] the influence of the slag viscosity on the slag splashing process was studied, and its conclusions are as follows: (i) ejection mechanism becomes dominant as viscosity is decreased; (ii) washing mechanism becomes dominant as viscosity is increased; (iii) efficiency of the slag splashing process is increased as slag viscosity decreases.

In this work the influence of the slag density on the slag splashing process is analyzed using computational fluid dynamics simulations. Values of the slag density ranging from 2000 to $3000 \mathrm{~kg} \mathrm{~m}^{-3}$ are considered. This range is typical of $\mathrm{CaO}-\mathrm{SiO}_{2}$ molten slags found in steelmaking [13]. Physical dimensions of the converter correspond to an actual industrial steelmaking converter of 150 metric tons. The volume fraction of slag in the converter sidewalls is employed for quantitative evaluation of the slag splashing efficiency. In order to detect spitting of slag from the converter mouth, the global mass balance is determined. Besides, the effect of the nitrogen jet Mach number on the slag splashing is simulated and discussed. Finally, a qualitative comparison between the computational fluid dynamics simulations and results from the literature is made.

\section{Mathematical Modeling}

During the slag splashing process, molten slag located in the converter bottom is splashed to the converter sidewalls by means of a supersonic jet of gaseous nitrogen. The momentum of the nitrogen jet is transferred to the molten slag, which causes the slag to be stirred and ejected by the action of a standing wave and high shear forces, respectively [4]. Predominance of one of the coating mechanisms, that is, washing or ejection, depends on factors such as the jet characteristics (velocity, exit angle), the operating conditions (lance height, molten slag depth) and the slag properties (viscosity, density, and temperature). Inertial, gravitational, viscous, and interfacial forces are applied on both phases, that is, gaseous nitrogen and molten slag, causing a nonisothermal multiphase flow. To model the complex system here considered, equations which govern the fluid flow, the mass balance, the turbulence, and the multiphase flow are required.

The flow of an incompressible newtonian fluid is governed by the Navier-Stokes equations, which in vector form are expressed as [14]:

$$
\rho\left(\frac{\partial \vec{u}}{\partial t}+\vec{u} \cdot \nabla \vec{u}\right)=-\nabla p+\mu_{\mathrm{eff}} \nabla^{2} \vec{u}+\rho \vec{g}+F
$$

where $\rho$ is the fluid density, $\vec{u}$ is the velocity vector, $t$ is time, $p$ is pressure, $\mu_{\mathrm{eff}}$ is the effective fluid viscosity, $\vec{g}$ is the gravity vector, and $F$ represents additional forces applied or acting on the fluid. To maintain the mass balance in the system, the continuity equation [14] must be solved:

$$
\frac{\partial u_{j}}{\partial x_{j}}=0
$$

where $u_{j}$ and $x_{j}$ are the $j$ th components of the velocity vector and the coordinate system, respectively.

Turbulence was simulated by means of the classical two equations $K-\varepsilon$ model [15]:

$$
\begin{aligned}
\rho v_{j} \frac{\partial K}{\partial x_{j}}= & \frac{\partial}{\partial x_{j}}\left(\frac{\mu_{t}}{\sigma_{K}} \frac{\partial K}{\partial x_{j}}\right)+\mu_{t} \frac{\partial v_{j}}{\partial x_{i}}\left(\frac{\partial v_{i}}{\partial x_{j}}+\frac{\partial v_{j}}{\partial x_{i}}\right)-\rho \varepsilon, \\
\rho v_{j} \frac{\partial \varepsilon}{\partial x_{j}}= & \frac{\partial}{\partial x_{j}}\left(\frac{\mu_{t}}{\sigma_{\varepsilon}} \frac{\partial \varepsilon}{\partial x_{j}}\right)+C_{1} \mu_{t} \frac{\varepsilon}{K} \frac{\partial v_{j}}{\partial x_{i}}\left(\frac{\partial v_{i}}{\partial x_{j}}+\frac{\partial v_{j}}{\partial x_{i}}\right) \\
& -C_{2} \frac{\varepsilon}{K} \rho \varepsilon
\end{aligned}
$$

where $K$ is the turbulent kinetic energy, $\varepsilon$ is the dissipation rate, and $\mu_{t}$ is the turbulent viscosity. Besides, $\sigma_{K}=1.0$, $\sigma_{\varepsilon}=1.3, C_{1}=1.44$, and $C_{2}=1.92$. The effective viscosity employed in the Navier-Stokes equations is determined from

$$
\mu_{\mathrm{eff}}=\mu_{0}+\mu_{t},
$$

where $\mu_{0}$ is the laminar viscosity. The turbulent viscosity is calculated from

$$
\mu_{t}=\frac{\rho C_{\mu} K^{2}}{\varepsilon},
$$

where $C_{\mu}=0.09$ and $K$ and $\varepsilon$ are determined from (3).

Boundary conditions at the inlet nozzles are determined as follows: for the velocity components, $u_{x}=U_{\text {in }} \sin (\alpha)$ and $u_{y}=U_{\text {in }} \cos (\alpha)$, where $U_{\text {in }}$ is the nominal velocity and $\alpha$ is the inlet angle of the nitrogen jet which corresponds to the exit angle of the nozzles. The inlet values of $K$ and $\varepsilon$ are determined from $[15,16]$

$$
\begin{aligned}
K_{\text {in }} & =0.01 U_{\text {in }}^{2}, \\
\varepsilon_{\text {in }} & =\frac{2 K_{\text {in }}^{1.5}}{D},
\end{aligned}
$$

where $D$ is the diameter of the inlet nozzle. At the converter walls the classical nonslip condition is applied.

When droplet breakaway occurs, there is a balance between the inertial $\left(F_{i}\right)$, interfacial $\left(F_{\gamma}\right)$, and gravitational forces $\left(F_{g}\right)[5,17]$ :

$$
F_{i}=F_{\gamma}+F_{g}
$$

The drop diameter $(d)$ derived from the balance of forces of $(7)$ is given by $[5,17]$ :

$$
d=\frac{3 U^{2}}{8 g}\left(1-\left(1-\frac{128 \gamma g}{3 \rho U^{4}}\right)\right),
$$

where $U$ is the magnitude of the jet velocity at the impact point and $\gamma$ is the surface tension. 


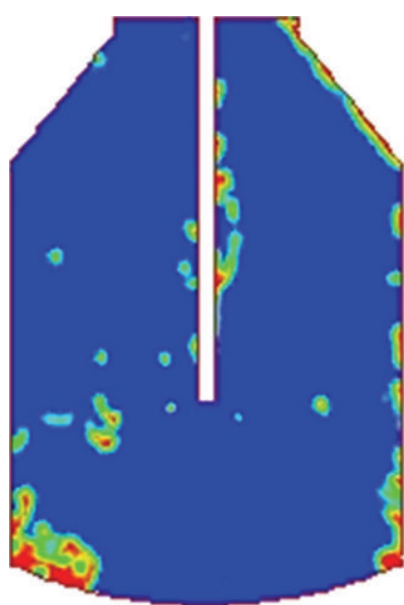

(a)

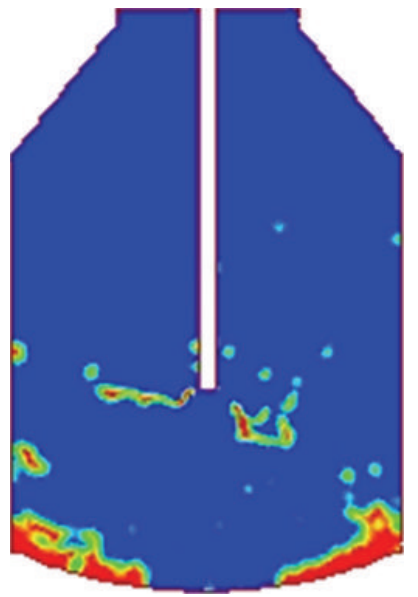

(d)

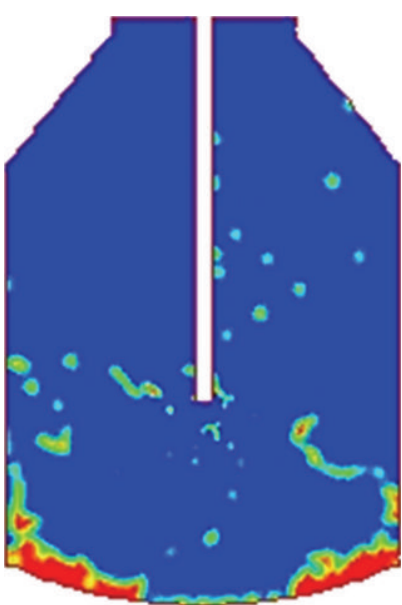

(b)

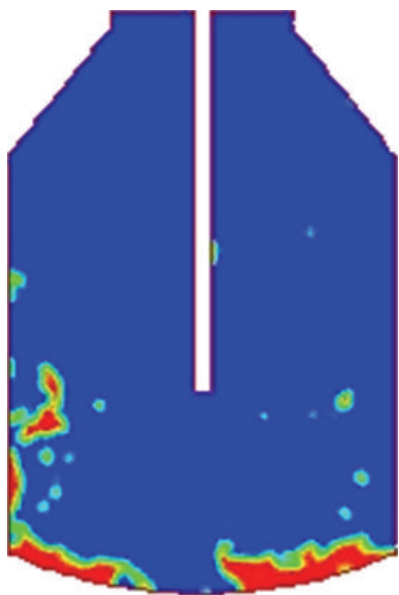

(e)

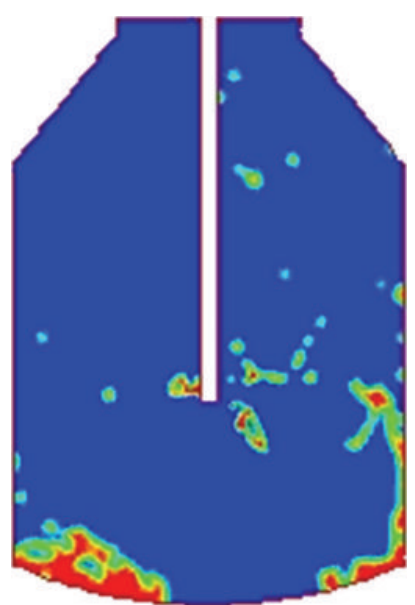

(c)

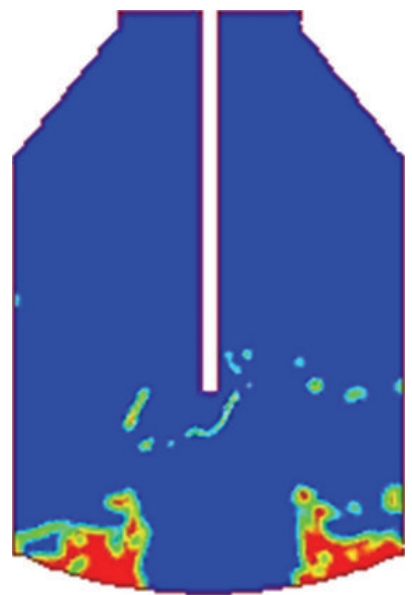

(f)

FIGURE 1: Distribution of phases for several values of the slag density (red is molten slag; blue is nitrogen). (a) 2000, (b) 2200, (c) 2400, (d) 2600, (e) 2800 , and (f) $3000 \mathrm{~kg} \mathrm{~m}^{-3}$.

The Volume of Fluid model is employed here to tackle the multiphase flow. This model is based on the assumption that two or more phases are not interpenetrating. Each $i$ th phase has associated a volume fraction $V_{i}$, and in every control volume the sum of the volume fractions of all phases is equal to 1. In the Volume of Fluid Model the tracking of the interface between the phases is accomplished by solving the continuity equation for each phase [18]:

$$
\frac{\partial V_{i}}{\partial t}+\vec{u} \cdot \nabla V_{i}=0
$$

To better define the slag-nitrogen interface, the computational fluid dynamics software (FLUENT) uses an interpolation scheme called Geometric Reconstruction Scheme.

\section{Computer Simulations}

Physical dimensions of the considered converter correspond to an actual industrial converter of 150 metric tons of capacity and were assumed as follows: height, $7.2 \mathrm{~m}$; diameter, $4.8 \mathrm{~m}$; lance diameter, $0.2 \mathrm{~m}$; number of nozzles, 2 ; diameter of nozzles, $0.043 \mathrm{~m}$; exit angle of nozzles, 10 degrees. The operating parameters were set as follows: lance height above the initial molten slag surface, $2 \mathrm{~m}$; velocity of the supersonic nitrogen jet, Mach 1.5; initial molten slag depth, $0.5 \mathrm{~m}$. Viscosity and surface tension of slag were assumed to be $0.5 \mathrm{~kg} \mathrm{~m}^{-1} \mathrm{~s}^{-1}$ and $0.4 \mathrm{~N} \mathrm{~m}^{-1}$, respectively.

To reduce the computational effort, an isothermal twodimensional converter was considered. The coupled NavierStokes equations, the continuity equation, the turbulence model, and the Volume of Fluid Model were numerically solved using computational fluid dynamics software (FLUENT). The Pressure Implicit Splitting Operation algorithm was employed in the transient simulations for the pressurevelocity coupling given that it maintains stability of the numerical scheme despite the larger time steps.

Transient isothermal two-dimensional computer simulations were carried out using a time step of $0.0001 \mathrm{~s}$ and a mesh consisting of 14075 trilateral cells. Due to the fast dynamics of the fluid flow, the integration time was $2 \mathrm{~s}$; in 


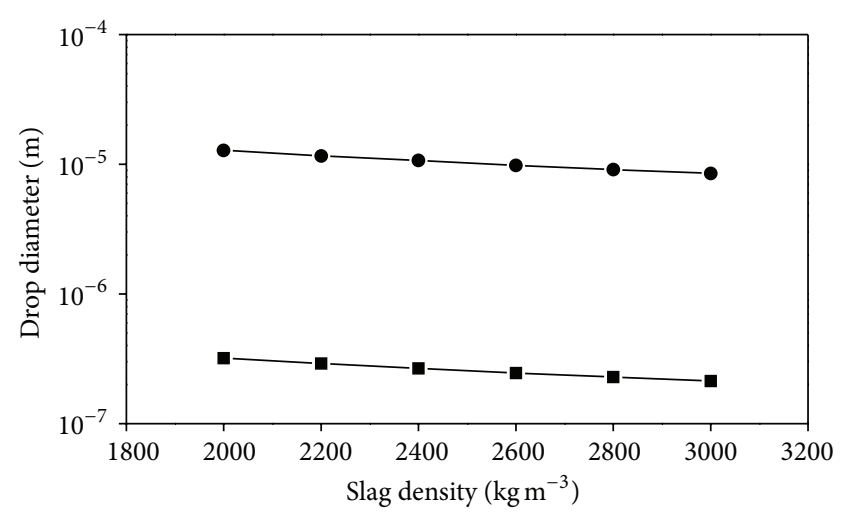

Figure 2: Diameter of the slag drops as a function of the slag density and the impact velocity: $50 \mathrm{~m} \mathrm{~s}^{-1}$ (circle) and $100 \mathrm{~m} \mathrm{~s}^{-1}$ (square).

this time the multiphase flow is fully developed. Viscosity and surface tension of the molten slag was assumed to be $0.5 \mathrm{~kg} \mathrm{~m}^{-1} \mathrm{~s}^{-1}$ and $0.4 \mathrm{~N} \mathrm{~m}^{-1}$, respectively. For the analysis, the slag density was varied from 2000 to $3000 \mathrm{~kg} \mathrm{~m}^{-3}$ using intervals of $200 \mathrm{~kg} \mathrm{~m}^{-3}$.

\section{Analysis of Results}

Figure 1 depicts the distribution of phases (red phase is molten slag; blue phase is nitrogen) for several values of the slag density using the operating conditions and integration time described in Section 3. It is observed that the ejection height of the slag drops decreases as the slag density is increased. This is explained by the small forces required by the less dense slag drops to be broken and ejected compared with the relatively big forces required by the denser slag. The ejection forces are supplied by the momentum of the nitrogen jet. Figure 1(a) shows that for a density of $2000 \mathrm{~kg} \mathrm{~m}^{-3}$ the slag reaches the top of the converter, and as result of this, spitting of slag from the mouth converter occurs. This can be corroborated from a global mass balance. A negative value of the global mass balance indicates that molten slag is being expelled from the converter. The spitting phenomenon does not occur for values of slag density equal or greater than $2200 \mathrm{~kg} \mathrm{~m}^{-3}$ under the conditions described above.

In Figure 2 the diameter of the slag drops as function of the slag density and the velocity of the jet at the impact site is shown. The drop diameters were obtained using (8), which is strongly nonlinear. The velocity of the jet decays as it descends towards the converter bottom and the slag bath is impacted at a subsonic velocity. The impact velocity $U$ of (8) was approximated from the contours of the velocity magnitude shown in Figure 3 corresponding to Figure 1(a). During the blowing the depth of the slag bath is reduced and the nitrogen jet covers a longer distance to impact the molten slag. Due to this the jet velocity suffers a significant decay below $200 \mathrm{~m} \mathrm{~s}^{-1}$. Then, two impact velocities were considered: 50 and $100 \mathrm{~m} \mathrm{~s}^{-1}$. It is observed that the drop diameter decreases in size as density is increased. A similar behavior is observed with respect to the impact velocity:

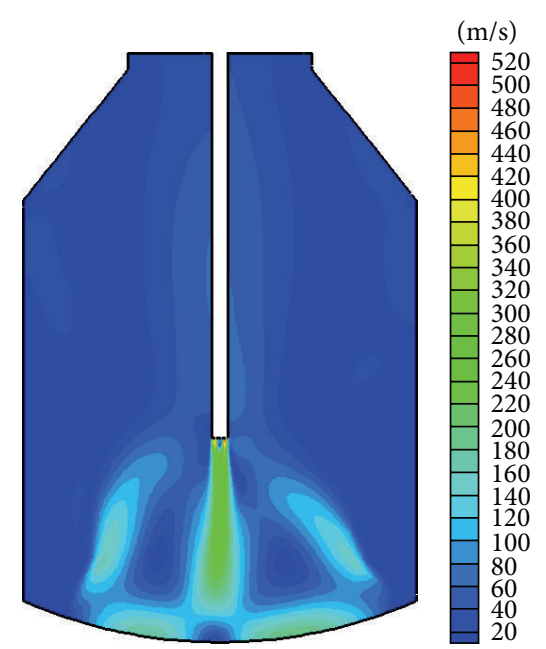

FIgure 3: Contours of velocity magnitude corresponding to Figure 1(a).

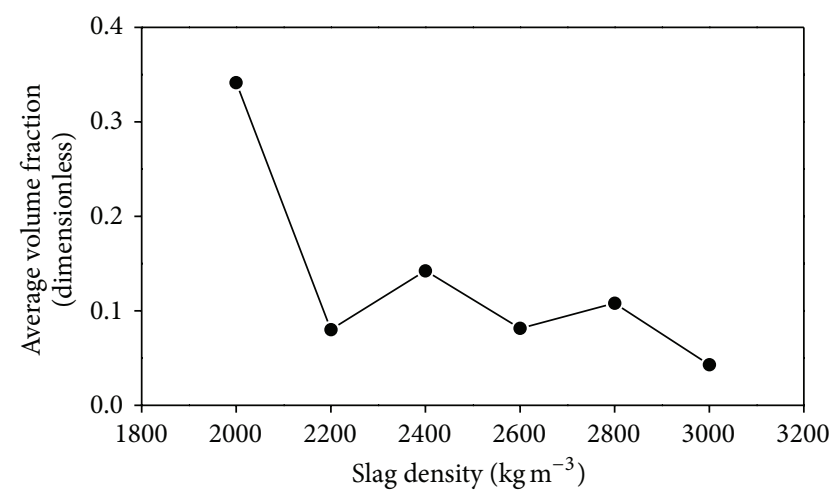

FIGURE 4: Average volume fraction on the converter side walls as a function of the slag density.

the drop diameter diminishes as the impact velocity grows. Results of Figure 2 explain the finding that the height reached by the ejected slag drops decreases as the slag density is increased.

Efficiency of the splashing process can be evaluated in terms of the magnitude of the converter sidewalls coated by slag. Full wall adhesion of slag droplets was considered in the numerical simulations. In order to evaluate in a quantitative way the splashing efficiency as function of the slag density, the average volume fraction of slag $\left(V_{s}\right)$ [12] in the sidewalls of the converter was determined. $V_{s}=1$ indicates that the sidewalls became fully coated by slag, whereas $V_{s}=0$ means that the sidewalls are not coated at all. Results are observed in Figure 4, where it is appreciated that the $V_{s}$ is enhanced with low slag density whereas it is worsened by large slag density. This is consistent with the results of Figure 1, which shows that the upper sections of the sidewalls are more coated as the slag density is decreased. Generally speaking, from Figure 1 it can be said that low slag density promotes the coating of the upper converter walls, whereas high density provides the protective coating of the lower walls. In spite 


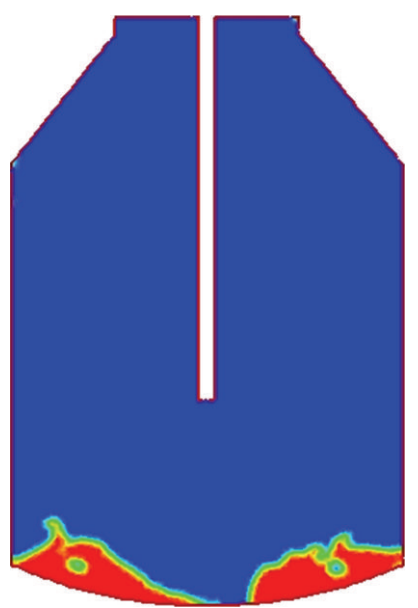

(a)

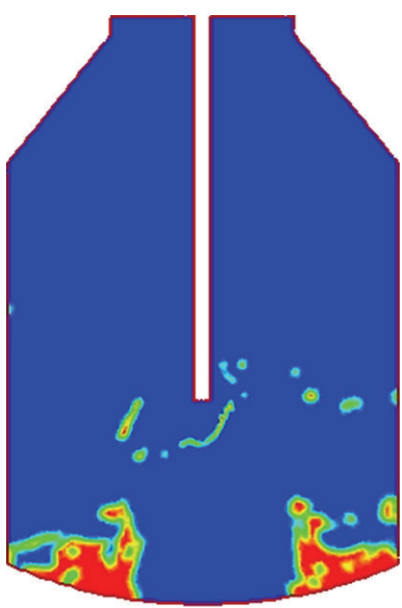

(b)

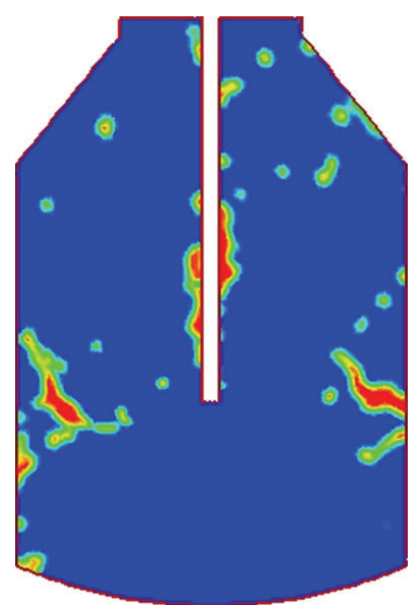

(c)

Figure 5: Distribution of phases for several values of the nitrogen jet velocity for a slag density of $3000 \mathrm{~kg} \mathrm{~m}^{-3}$ (red is molten slag; blue is nitrogen) (a) Mach 1, (b) Mach 1.5, and (c) Mach 2.

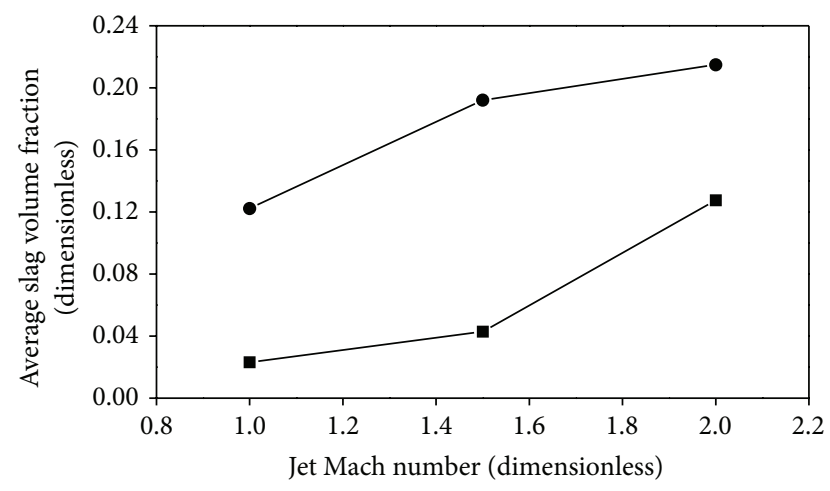

FIGURE 6: Average volume fraction on the converter side walls as function of the jet Mach number. Slag density: $2000 \mathrm{~kg} \mathrm{~m}^{-3}$ (circle), $3000 \mathrm{~kg} \mathrm{~s}^{-1}$ (square).

of the splashing efficiency is enhanced with low slag density, a serious operational drawback arises given that low density promotes the undesirable spitting phenomenon.

The negative effect of the high slag density on the splashing efficiency can be counteracted by increasing the nitrogen jet velocity given that high jet velocity provides additional momentum forces to enhance the formation small drops of the denser slag. Small drops are able to reach the top of the converter, promoting the coating of the upper sidewalls. This is visually appreciated in Figure 5, which illustrate that the ejection height of the slag drops increase as the nitrogen jet velocity is increased. Figure 6 shows that the volume fraction of slag at the converter sidewall is increased as the jet velocity is increased. However, this effect is magnified if the slag density is low. From an operational viewpoint this means that coating the extent of the upper sidewalls can be increased by (i) increasing the jet velocity or (ii) decreasing the slag density.

In accordance with [5], experimental studies report that the volume of slag splashed decreases with increasing slag density. This is explained by the fact that the Momentum number and the Weber number, which determine slag droplet generation, are dependent upon $\rho^{-1}$ and $\rho^{-0.5}$, respectively. The experimental results reported in [5] are in agreement with the numerical results of this work, particularly with those results shown in Figure 1.

\section{Conclusions}

The slag splashing process in steelmaking converters was modeled and simulated by means of computational fluid dynamics. Particularly, in this work the effect of the slag density on the splashing efficiency is studied and discussed. The drop diameter of the resulting drops depends inversely on both the slag density and the jet impact velocity. Low density yields high efficiency of the considered process, unfortunately low density promotes the emergence of undesirable spitting phenomenon too. High density decreases the efficiency of the splashing process; however this negative effect can be counteracted by increasing the jet velocity given that additional inertial forces are provided.

\section{Conflict of Interests}

The authors declare that there is no conflict of interests regarding the publication of this paper.

\section{References}

[1] C. J. Messina and J. R. Paules, "The worldwide status of BOF slag splashing practices and performance," in Proceedings of the 79th Steelmaking Conference, pp. 153-155, Pittsburgh, Pa, USA, March 1996.

[2] K. M. Goodson, N. Donaghy, and R. O. Russell, "Furnace refractory maintenance and slag splashing," Iron and Steelmaker, vol. 22, no. 6, pp. 31-34, 1995. 
[3] T. R. Galiullin, E. V. Protopopov, V. V. Sokolov, and A. G. Chernyatevich, "Gas-jet conditions in the slag coating of oxygen-converter linings," Steel in Translation, vol. 38, no. 2, pp. 97-100, 2008

[4] K. D. Peaslee, "Physical modeling of slag splashing in the BOF," Iron and Steel Engineer, vol. 73, no. 11, pp. 33-37, 1996.

[5] K. C. Mills, Y. Su, A. B. Fox, Z. Li, R. P. Thackray, and H. T. Tsai, "A review of slag splashing," ISIJ International, vol. 45, no. 5, pp. 619-633, 2005.

[6] M. J. Luomala, T. M. J. Fabritius, E. O. Virtanen et al., "Physical model study of selective slag splashing in the BOF," ISIJ International, vol. 42, no. 11, pp. 1219-1224, 2002.

[7] K. D. Peaslee and W. Chen, "Important factors for effective slag splashing," in Proceedings of the CIM Conference, Edmonton, Canada, 2004.

[8] L. Salinas and R. Fuentes, "Interaction between a gaseous vertical jet and a liquid surface-a theoretical and experimental study," in Proceedings of the Copper 99-Cobre 99 International Conference, Phoenix, Ariz, USA, October 1999.

[9] A. Nguyen and G. Evans, "Computational fluid dynamics modelling of gas jets impinging onto liquid pools," Applied Mathematical Modelling, vol. 30, no. 11, pp. 1472-1484, 2006.

[10] M. Ersson, A. Tilliander, L. Jonsson, and P. Jönsson, "A mathematical model of an impinging air jet on a water surface," ISIJ International, vol. 48, no. 4, pp. 377-384, 2008.

[11] M. A. Barron and I. Hilerio, "Computer simulation of slag splashing in a steelmaking converter," in Proceedings of the World Congress in Computer Science, Computer Engineering and Applied Computing, Las Vegas, Nev, USA, 2011.

[12] M. A. Barron, D. Y. Medina, and I. Hilerio, "CFD analysis of influence of slag viscosity on the splashing process in an oxygen steelmaking converter," Modeling and Numerical Simulation of Material Science, pp. 90-93, 2013.

[13] R. J. Fruehan, The Making, Shaping and Treating of Steel, Steelmaking and Refining Volume, AISE Steel Foundation, Pittsburgh, Pa, USA, 11th edition, 1998.

[14] R. B. Bird, W. E. Stewart, and E. N. Lightfoot, Transport Phenomena, John Wiley \& Sons, New York, NY, USA, 2nd edition, 2002.

[15] B. G. Thomas, Q. Yuan, S. Sivaramakrishnan, T. Shi, S. P. Vanka, and M. B. Assar, "Comparison of four methods to evaluate fluid velocities in a continuous slab casting mold," ISIJ International, vol. 41, no. 10, pp. 1262-1271, 2001.

[16] G. Solorio-Díaz, R. D. Morales, J. Palafax-Ramos, L. GarcíaDemedices, and A. Ramos-Banderas, "Analysis of fluid flow turbulence in tundishes fed by a swirling ladle shroud," ISIJ International, vol. 44, no. 6, pp. 1024-1032, 2004.

[17] P. C. Mahapatra, S. Majumdar, R. Shrinivas et al., "Understanding slag splashing technology in BOF," SEAISI Quarterly, vol. 29, no. 4 , pp. 54-60, 2000.

[18] C. W. Hirt and B. D. Nichols, "Volume of fluid (VOF) method for the dynamics of free boundaries," Journal of Computational Physics, vol. 39, no. 1, pp. 201-225, 1981. 

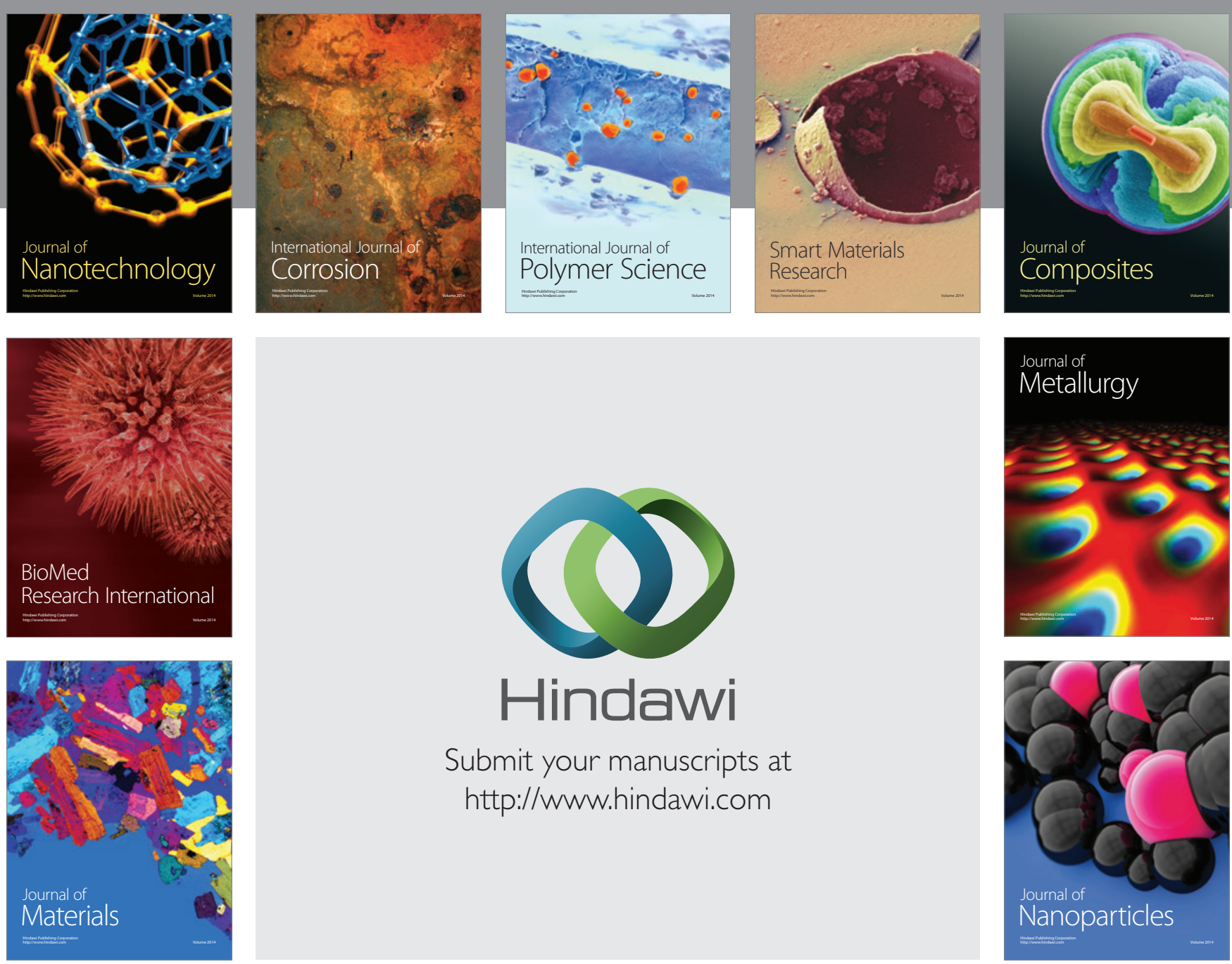

Submit your manuscripts at http://www.hindawi.com
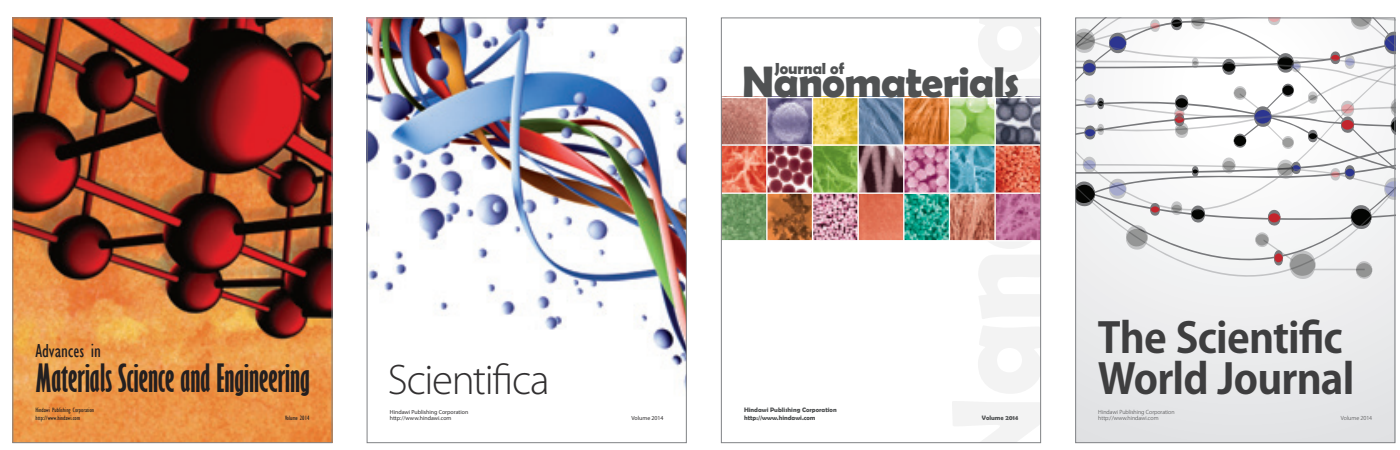

\section{The Scientific World Journal}
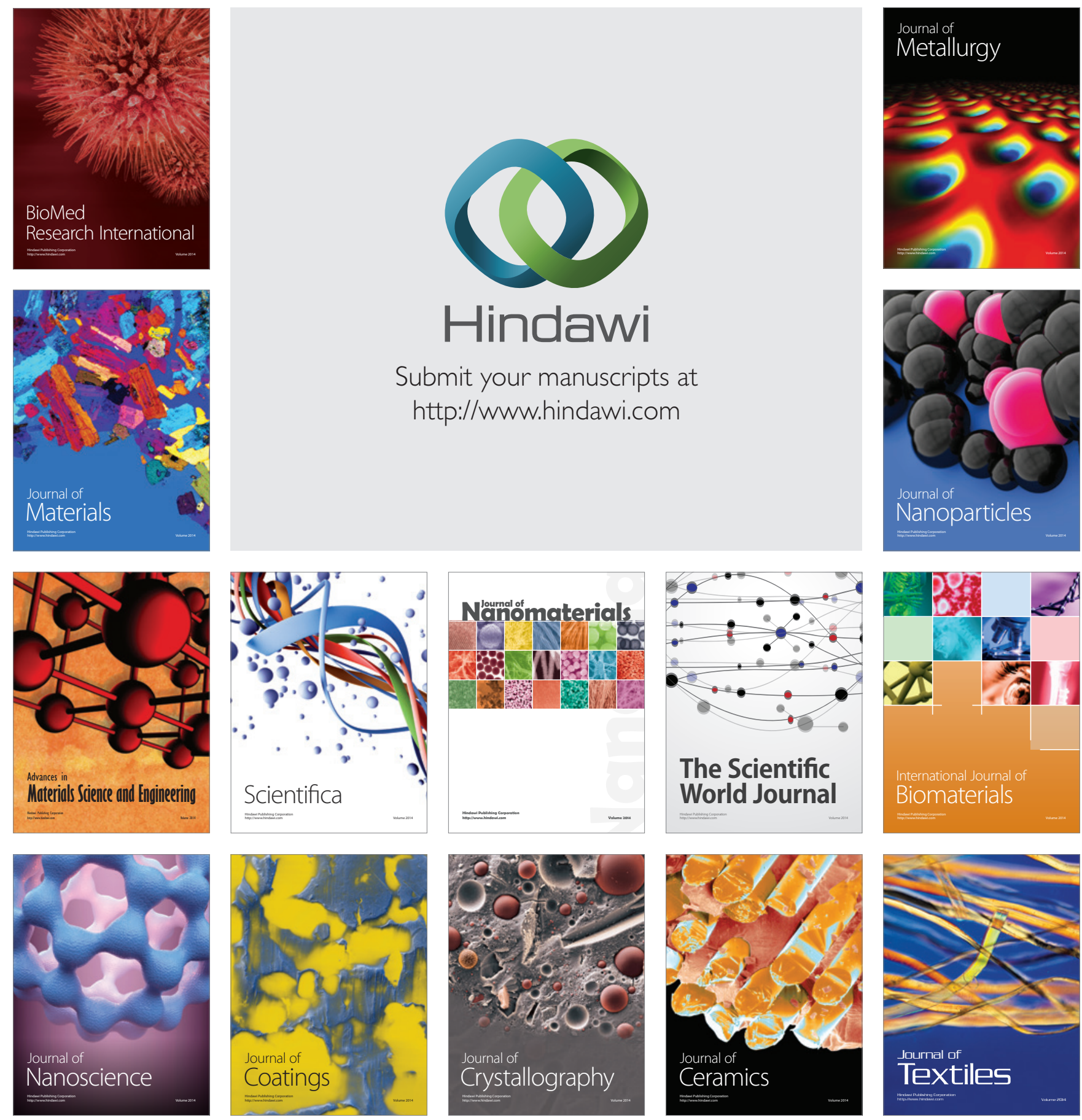